\title{
ESTAÇÃO FERROVIÁRIA DE REGENTE FEIJÓ - SP: HISTÓRIA E ARQUITETURA
}

\author{
Daniel Boscoli, Maria Eduarda Henares, Gabriela Ribeiro, Mayara Pissutti Albano \\ Universidade do Oeste Paulista - UNOESTE. Curso de Arquitetura e Urbanismo, Presidente Prudente - SP.E-mail: \\ ma.albano@unoeste.br
}

\section{RESUMO}

O presente artigo tem como objetivo apresentar um levantamento da história do edifício da antiga Estação Ferroviária da cidade de Regente Feijó e de sua Arquitetura, relacionando-o com a história da Estrada de Ferro Sorocabana. O edifício é de importância histórica, pois foi através da ferrovia que frentes pioneiras desbravaram o sertão paulista, ou seja, trata-se de um marco da colonização nessa região. As ferrovias, de modo geral, possuem grande importância no processo de desenvolvimento de muitas cidades brasileiras, pois através delas "chegavam" desenvolvimento político, econômico e cultural, sendo assim, são consideradas patrimônio histórico e cultural. A metodologia baseia-se em pesquisas bibliográficas e documentais sobre a história da ferrovia no estado de São Paulo, e em especial no oeste paulista; patrimônio histórico; bem como levantamentos in loco dos edifícios do complexo ferroviário na referida cidade.

Palavras-chave: Estação ferroviária, Patrimônio Histórico e Cultural, Regente Feijó.

\section{REGENT FEIJÓ'S RAILWAY STATION - SP: HISTORY AND ARCHITECTURE}

\begin{abstract}
This Article aims to present a survey of the history of the building of the former railway station of the city of RegenteFeijo and its architecture, linking it to the history of the Sorocabana's railroad. The building have historical importance because it was by railroad that pioneer fronts paved the São Paulo's backcountry, ie, it is a landmark of colonization in this region. The railroads, in general, have great importance in the development of many Brazilian cities process because through them "arrived" political, economic and cultural development, thus, are considered historical and cultural heritage. The methodology is based on bibliographic and documentary research on the history of the railroad in the state of São Paulo, and especially in the west side of São Paulo; heritage; well as surveys in loco rail complex of buildings in that city.
\end{abstract}

Keywords: Railway Station, RegenteFeijo, History and Cultural Heritage. 


\section{INTRODUÇÃO}

A expansão da estrada de Ferro no Estado de São Paulo, ocorrida na segunda metade do século XIX, foi um marco no rompimento das barreiras espaciais da produção cafeeira, que impediam a economia se expandir para o interior do estado. Com o passar do tempo, e a chegada da crise da economia agrícola e de sua exportação, o avanço daindustrialização, o transporte rodoviário, através do uso de caminhões, se tornou elemento de integração regional, função que a ferrovia não conseguiu cumprir. Desta feita, inicia-se um intenso processo de desestruturação do setor, que culminou no abandono intenso e no sucateamento da malha ferroviária paulista já observado no final da década de 1980 (MARQUES, 2009).

A Estrada de Ferro Sorocabana, fundada em 1872, era uma das quatro grandes Companhias férreas de sua época. Chegou ao oeste paulista através da expansão de sua linha-tronco até 1922. Segundo Passarelli (2006), as estações ferroviárias foram responsáveis pelas primeiras atividades urbanas, influenciaram o estabelecimento do traçado urbano, e o desenvolvimento de diversos setores.

As ferrovias têm grande importância para as cidades do oeste paulista, visto que representaram o meio de chegada do desenvolvimento econômico, político e cultural. Por esse motivo, são consideradas patrimônio histórico e cultural, simbolizando uma referência ao passado, e por isso é importante preservar sua memória (DUMCZUK e MONASTIRSKY, 2010).

Os patrimônios culturais também representam a memória de uma sociedade, sendo representados por bens materiais e imateriais com valor relevante. Para Claval (2002) e Bourdier (2001), o patrimônio cultural proporciona aos membros de uma sociedade um poder de pertencimento, já que este, associado a uma base territorial, constrói a identidade cultural.

Por ser visto como uma referência ao passado, o patrimônio, de maneira geral, é merecedor de proteção, e faz com que lugares históricos, estilos arquitetônicos, artes tradicionais, festas, costumes e tradições não percam o seu valor e sejam repassados às gerações futuras (DEMCZUK e MONASTIRSKY, 2010). Portanto é possível perceber a ligação entre o patrimônio cultural ferroviário e a identidade das localidades. Preservar, no entanto, não significa estagnar e paralisar investimentos (RIBEIRO, 2005). É possível adaptar velhas construções para atividades atuais dando-as funções compatíveis, valorizando o imóvel e o entorno.

Pensando na questão da memória coletiva como parte da construção da identidade de uma comunidade e, consequentemente, da construção do patrimônio cultural, tomamos como tema de 
pesquisa a estação Ferroviária da cidade de Regente Feijó - SP, pertencente aEstrada de Ferro Sorocabana.

Os objetivos são discutir a importância históricada Estrada de Ferro Sorocabana e a Estação Ferroviária de Regente Feijó, relacionando-as com a expansão do Oeste Paulista. E discussão sobre o estado de conservação das edificações - estações, pátios e habitações e seu entorno.Verificação das condições do patrimônio ferroviário que possa servir futuramente à uma proposta de reciclagem arquitetônica.

A metodologia baseia-se em levantamentos bibliográfico buscando o aprofundamento acerca dos temas relacionados a pesquisa, pesquisa documental, através de materiais do Museu da Estrada de Ferro Sorocabana e também levantamentos in loco, à partir da observação direta intensiva.

\section{HISTÓRIA}

A Estação de Ferro da Memória, nome primitivo da Estação de Ferro de Regente Feijó, foi inaugurada, segundo documentos da EFS (Estrada de Ferro Sorocabana), em 15 de janeiro de 1919. De acordo com a revista Ilustração Nossa Estrada (edição 293, 1962), o projeto original da ferrovia foi solicitado por Luiz Matheus Maylaski à Companhia Sorocabana para escoar a produção de cimento de uma fabrica na região de Sorocaba para São Paulo, um trecho que ao todo somaria $132 \mathrm{Km}$. Todavia, a expansão das plantações de café e das criações pastoris mais ao interior desta província e de Mato Grosso, incentivaram a extensão da linha férrea. Esta expansão, de acordo com Soukef (2001), levou a ferrovia até a então Vila de Botucatu onde encontrou a Companhia Ituana,fato que proporcionou a fusão das mesmas, gerando a Companhia União Sorocabana e Ituana em 1892.

Sua expansão foi interrompida pela forte crise econômica do inicio do século $X X$, sendo a Companhia arrematada pelo Governo Federal em 1904 e em 1905 vendida ao Governo do estado de São Paulo (DEL RIOS,1992apud DALTOZO, 2008).Em 1919, ano da inauguração da Estação de Trem da Memória, a obra era pública pelo fato da linha ser de propriedade do Governo estado, tendo como principal função o escoamento da produção agropastoril da região e do estado do Mato Grosso, posto de abastecimento de lenha e água, além de razões politico-militares. O longo tempo entre seu planejamento e sua conclusão se deu à morosidade conferida aos processos após a concessão do trecho a um grupo franco americano e posteriormente a gripe espanhola que assolou o país, sendo inaugurada apenas como um posto de abastecimento de lenha e água para aslocomotivas, de acordo com a Revista Ilustração nossa Estrada (edição 293, 1962). 


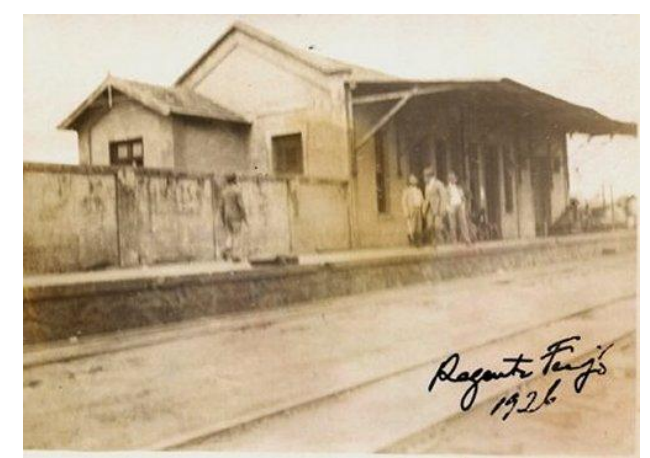

Figura 1. Estação da Memória - Regente Feijó no início do século XX.

Fonte:http://www.estacoesferroviarias.com.br/r/regfeijo.html

A estrada de ferro e consequentemente sua estação, foram responsáveis pela espacialização de Regente Feijó, assim como a maioria das demais estações das outras cidades na região fizeram. 0 som causado pelas locomotivas não somente afugentou a população indígena da região que consequentemente recuou em suas investidas contra os pioneiros brancos,lideres da marcha pioneira, mas também proporcionou o escoamento da produção e gerou o desenho urbano. Em 1922 com a doação de terras para a formação de um povoadono entorno da estação, já existiam elementos de um lugarejo urbano com armazéns, farmácias, pensões e moradias.

Os Guias de Horário da EFS afirmam que trens de carga e de passageiros, fizeram escala na Estação de Trem da Memória entre 1919 e 1999.Tornou-se primeiramente Distrito da Memória, e posteriormente município em 28 de junho de 1935 através do decreto número 7.262 do governador do estado Armando de Salles Oliveira.

\section{ARQUITETURA}

A estação situa-se junto na Avenida Regente Feijó sem número, hoje a região representa um local de permanência provisória por ter sua fachada principal orientada para as áreas de embarque da estação rodoviária da cidade.

Os edifícios são utilizados como ponto de encontro de idosospara aulas de artesanato (Clube da Terceira Idade "Sempre Amigos"), um centro de reciclagem e também um posto de saúde (ESF Estratégia de Saúde da Família - Fepasa), porém devido ao bloqueio visualgerado pela estação rodoviária da supracitada cidade, ela não possui um destaque e cuidados merecidos em função do valor histórico que possui, pois está isolada da cidade pela área de manobra da estação rodoviária. Pelo mesmo motivo, não há relação com outros espaços públicos de atração e apropriação no 
entorno como a praça da cidade inaugurada em 1933 e construída por Presidente Prudente quando ainda não havia se tornado município. (D'INCAO 2007apudDALTOZO,2008).

O prédio construído em 1919 (figura 2.A), que visivelmente passou por reformas que alteraram sua característica estética possui cobertura em duas águas com telhas coloniais de barro e a cobertura da plataforma em telhas de fibrocimento apoiadas sobre mão francesa metálica. A edificação ao lado (figura 2.B) possui características similares, ficando evidente apenas que a cobertura de telha coloniais de barro abrange o total da edificação e encontra-se sobre duas águas formando um beiral também apoiado sobre mãos francesas de madeira que cobrem tanto a entrada orientada para a Avenida Regente Feijó quanto à plataforma de embarque e carga. Ambos os edifícios são levantados em tijolos maciços sendo que no primeiro os mesmos são aparentes e no segundo não, os pisos de ambos são de cimento queimado e encerado.

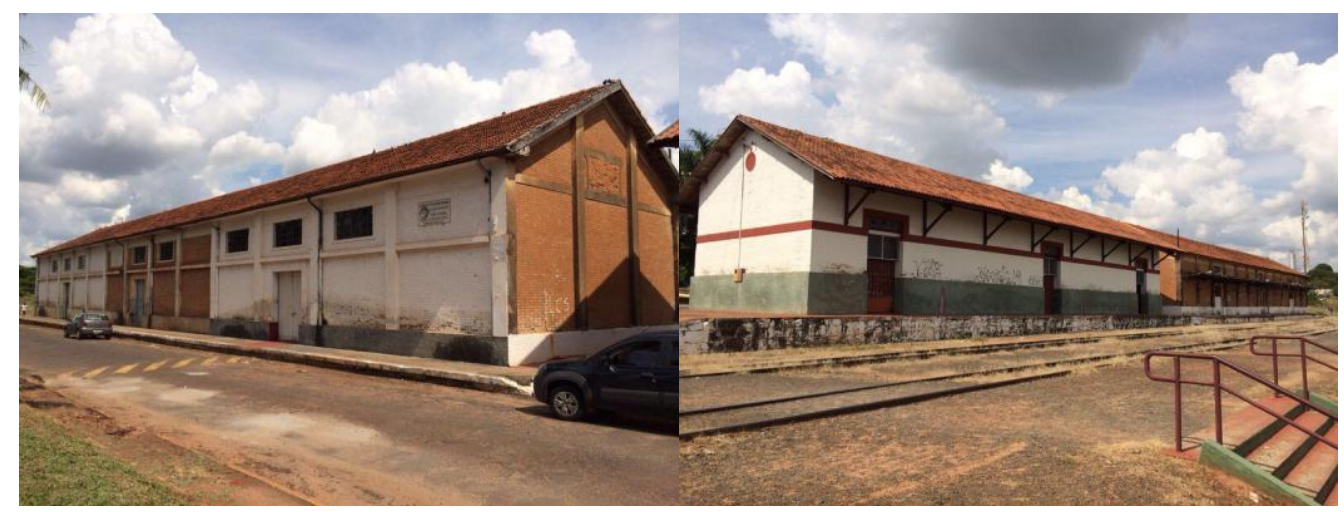

Figura 2.

A

B

Fonte: Autores, 2014.

O prédio construído em 1960 possui características distintas de acabamento, se assemelha aos demais pois está implantado longitudinalmente, possui formato retangular, e também possui mãos francesas, no entanto elas são de concreto coberto por telhas de fibrocimento, os acabamentos são diferenciados podendo ser notado à aplicação do reboco em chapisco e materiais que não permitem a visualização do material utilizado como alvenaria, o piso é todo em ladrilho hidráulico vermelho liso. 


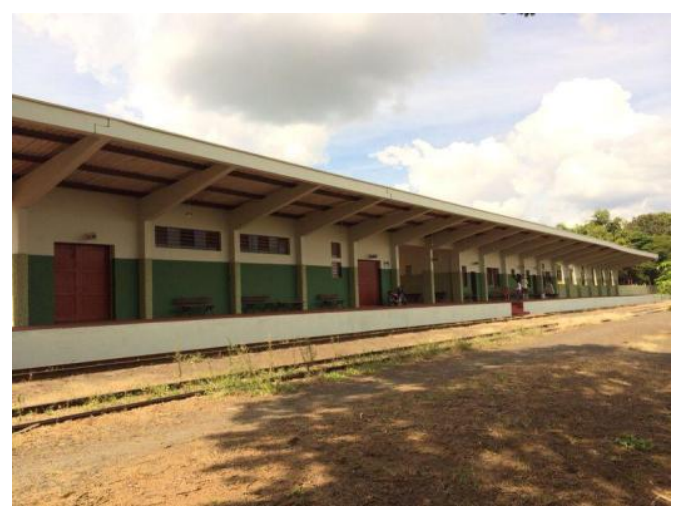

Figura 3. Edificação da década de 1960

Fonte: Autores, 2014.

Esta edificação tem como ponto central o saguão, que mesmo extremamente simples espacializa todas as funções ali desempenhadas, hoje como posto de saúde, no passado como estação férrea. Os edifícios das estações de Regente Feijó são de difícil filiação estilística devido ao seu caráter arquitetônico voltado à praticidade e funcionalidade da tipologia, sendo caracterizada como modesta e mais atrelada à função, o que segundo o Artigo 10 da Carta de Veneza (1964, p. 1), não deixa de ter valor:

"A noção de monumento histórico compreende a criação arquitetônica isolada, bem como o sitio urbano ou rural que dá testemunho de uma civilização particular, de uma evolução significativa ou de um acontecimento histórico. Entende-se não só às grandes criações, mas também às obras modestas, que tenham adquirido, com o tempo, uma significação cultural."

Arquitetura de baixo valor estético e grande valor histórico, a estação de Regente Feijó possui implantação longitudinal retangular, devido a seu projeto ser estritamente ligado à função.

Os edifícios da estação ferroviária de Regente Feijó estão bastante deteriorados devido ao abandono ao qual foram submetidos após a inauguração da nova estação em 1960. O edifício inaugurado em 1919 encontra-se com rachaduras nas estruturas, reboco descascado, falhas nas estruturas de cobertura e beiral, e rachaduras nos pisos. A pintura deste prédio também se encontra bastante deteriorada, com manchas de infiltração e pichação. O edifício onde funciona Clube da Terceira Idade "Sempre Amigos", possui manchas de infiltração e pichação, porém sem falhas aparentes em acabamento, piso e estrutura. A edificação onde hoje funciona o PSF foi reformada em 2003, portanto com nenhum dano aparente.

As alterações realizadas não foram documentadas, apenas registros fotográficos de má qualidade atestam o real estado da estação após alguns anos da sua inauguração, sendo que as 
alterações realizadas na mesma não alteraram seu valor estético, já que a Estação de Trem da Memória tem sua filiação estilística atrelada à arquitetura da função, sem apelos estéticos mas sim funcionais.

A estação levantada alguns metros em 1960 possui outras características de fachada, entretanto também se enquadra no posicionamento acima, sendo que a reforma documentada em 2003 não alterou seu padrão estético.

\section{CONSIDERAÇÕES FINAIS}

A ferrovia foi uma grande impulsora da colonização do oeste paulista em direção ao rio Paraná, em torno das estações desenvolveram diversas cidades da região, assim como Regente Feijó, portanto o conjunto ferroviário é assas importante para a história local. Com o passar dos anos, a decadência do sistema ferroviário no Brasil, muitas das estações foram esquecidas, os conjuntos arquitetônicos deteriorados e por vezes deixados sem uso, ou ocupados por atividades que corroboram com sua destruição. O levantamento da história e dos edifícios levanta a importância de tais elementose a necessidade de cuidados adequados.

O complexo ferroviário de Regente Feijó é um exemplo do uso inadequado do espaço, pois uma usina de reciclagem pode causar danos ao edifício, e também é um espaço do abandono, visto que a cidade se virou de costas para o espaço e o escondeu atrás do pátio de manobra da rodoviária.

Conclui-se que é latente iniciativas de revitalização do complexo ferroviário, para ressaltar a importância histórica que ele possui.

\section{REFERÊNCIAS}

BOURDIEU, Pierre. O poder simbólico. 5ạ ed. Rio de Janeiro: Bertrand Brasil, 2002.

CLAVAL, Paul. A geografia cultural. Florianópolis: Ed. da UFSC, 2001.

DALTOZO, José Carlos. Nos Trilhos da História. Presidente Prudente: Editora IMPRESS Gráfica e Editora, 2008.

D'INCAO, Maria Angela. Presidente Prudente - Capital Regional. Presidente Prudente: Editora Maria Angela D' Incao, 2007.

DEMCZUK, Paula G.; MONASTIRSKY, Leonel Brizolla. Ferrovia e memória: reflexões sobre a ferrovia em Irati-Pr e seu uso como produto turístico. In: Revista Discente Expressões Geográficas, n. 6, ano VI, P. 71 - 89. Florianópolis, junho 2010. 
MARQUES, P. P. Técnica, modernização e produção do espaço: um estudo sobre o papel da estrada de ferro nas transformações sócio-espaciais da Zona Alta Sorocabana. Dissertação de Mestrado Faculdade de Filosofia, Letras e Ciências Humanas. Universidade de São Paulo, São Paulo, 2009.

PASSARLLI, Silvia H. F. Paisagem ferroviária: memória e identidade da metrópole paulistana. In: Revista Exacta, São Paulo, v. 4, n. 2, p.363 - 373, jul/dez, 2006.

Prefeitura de Regente Feijó. História da cidade. Disponível em: http://www.regentefeijo.sp.gov.br/index.php?pg=historia. Acesso em: 20 de março de 2014.

SOUKEF JUNIOR, Antonio. Sorocabana Uma Saga Ferroviária. 01. ed. São Paulo: Dialeto Latin American Documentary, 2001.

Revista Nossa Estrada e documentos da EFS acessados através de acervo cedido pelo Museu EFS, Sorocaba-SP.

Congresso Internacional de Arquitetos e Técnicos dos Monumentos Históricos ICOMOS - Conselho Internacional de Monumentos e Sítios. Carta de Veneza. Veneza, 1964. 